\title{
The relationship of sensorimotor and function with activities of daily living and disease specific parametres in patients with rheumatoid arthritis
}

\author{
(DSongül Keskin Kavak ${ }^{1}$, Nebahat Sezer ${ }^{2}$, @Lale Aktekin ${ }^{2}$ \\ ${ }^{1}$ University of Health Sciences' Dr. Abdurrahman Yurtaslan Ankara Oncology Training and Research Hospital, Department of Physical Therapy \\ and Rehabilitation, Ankara, Turkey \\ ${ }^{2}$ Ankara Ylldırım Beyazıt University Faculty of Medicine, Department of Physical Therapy and Rehabilitation, Ankara, Turkey
}

Cite this article as: Keskin Kavak S, Sezer N, Aktekin L. The relationship of sensorimotor and function with activities of dailyliving and disease specific parametres in patients with rheumatoid arthritis. J Health Sci Med 2021; 4(6): 784-789.

\begin{abstract}
Objective: To evaluate the level of effect on the sensorimotor functions of the hand in patients with rheumatoid arthritis (RA) and investigate the relationship between this level and patients' daily life activities and disease-specific parameters.

Material and Method: This case-control study involved the evaluation of 80 patients with RA and 50 healthy volunteers aged 20-65 years. The coarse and fine grip strength of the patients was evaluated with hand dynamometer and pinch meter. The sensory evaluation of the hand was undertaken using the Semmes-Weinstein monofilament test (SWMT). The hand skill level was evaluated with Duru Oz Hand Index (DHI). The daily living activities of the patients were investigated using the Health Assessment Questionnaire (HAQ). The Disease Activity Score 28 (DAS28) was used to evaluate disease activity.

Results: The mean DAS28 score of the RA group was at a mild level (DAS $28<3.2$ ). No statistically significant difference was found between the RA group and the control group in terms of daily life activities (HAQ scores). The grip strength and the hand skill level (DHI) were statistically significantly lower in the RA group compared to the control group. In the sensory examination of the RA group using SWMT, while $83 \%$ of the patients were evaluated as normal, $15 \%$ were determined to have diminished light touch sensation. However, there was no statistical difference between the RA and control groups in terms of sensory evaluation.

Conclusion: As a result of the quantitative evaluations used in our study, the RA group was determined to have impaired fine skills and grip strength. Consistent with the literature, these findings had a negative effect on the daily life activities and function of these patients. In our knowledge there is no study with SMWT in RA patients. In our study, there wasn't statistical difference between the RA and control groups in terms of sensory evaluation with SMWT. Because of our patients have low disease activity, further studies are needed in patients with higher disease activity for evaluation sensorial functions.
\end{abstract}

Keywords: Rheumatoid arthritis, health assessment questionnaire, disease activity score, Semmes-Weinstein monofilament test

\section{INTRODUCTION}

Rheumatoid arthritis (RA) is a systemic disease characterized by symmetrical chronic arthritis that can affect all synovial joints, especially the wrist and small joints of the hand $(1,2)$. Impairment of anatomical integrity, limitations in the range of motion, loss of muscle strength, possible sensory problems, pain, and swelling are the main problems that impair the ability to use hands in RA $(1,3)$.

Since the focus is mostly on pain and inflammation control in patients with RA, a sensorimotor evaluation can be overlooked. In this study, we aimed to evaluate the level of effect on the sensorimotor functions of the hand in patients with RA and to investigate the relationship between this level and patients' daily life activities and disease-specific parameters $(4,5)$. Accordingly, it is very important to perform detailed motor and sensory examinations in this patient group. Since impairment in the hand functions of these patients can negatively affect their daily lives and make them dependent on others, they should be closely monitored and early rehabilitative treatment methods should be applied before the loss of function $(6,7)$. 


\section{MATERIAL AND METHOD}

The study was carried out with the permission of Ankara Yildırım Beyazıt University Faculty of Medicine Clinical Researchs Ethics Committee (Date: 17/12/2014, Decision No: 243). All procedures were carried out in accordance with the ethical rules and the principles of the Declaration of Helsinki.

This case-control study involved the evaluation of 80 patients diagnosed with RA and 50 healthy volunteers that presented to the physical medicine and rehabilitation outpatient clinic of Training and Research Hospital between January 2015 and June 2015. All individuals were informed about the study and signed the informed consent form. Patients who were diagnosed with RA according to the EULAR/ACR criteria and had cognitive function sufficient to comprehend evaluations to be made during the study were included in the sample while those with orthopedic, traumatic, neurological and endocrinological disorders that previously caused sensory or motor impairment in the hand and upper extremities were excluded.

\section{Hand Function Assessment}

The Duru öz Hand Index (DHI) was used to evaluate the fine skill functions of the hands.

DHI is a self-reported questionnaire developed to evaluate the hand function limitations of patients with RA. It consists of 18 items inquiring about hand skills in kitchen, dressing, personal hygiene and work activities and other general movements. The function of both hands is scored as follows $=0-40$ for kitchen work, $0-10$ for dressing, hygiene and office work, and 0-20 for the 'other' category. The score ranges between 0 (no difficulty) and 5 (impossible) in performing daily life activities. $(8,9)$

The Semmes-Weinstein monofilament test (SWMT) was used for the sensory evaluation of the hands. SWMT is a diagnostic test used to reveal sensory problems and objectively measure the touch threshold. SWMT has two kits of 20 and five pieces. In the current study, the patients were evaluated with a monofilament set consisting of five monofilaments at four different power levels. In this set, the green monofilament $(\log 1.65-2.83)$ is evaluated as normal, blue monofilament $(\log 3.22$ 3.61) as diminished light touch, purple monofilament (log3.84-4.31) as diminished protective sensation, red monofilament $(\log 4.56-6.65)$ as loss of protective sensation, and white monofilament $(>\log 6.65)$ as un detectable sensation.

Grip strength was evaluated with a digital hand dynamometer and pinch meter. A Baseline $e^{\otimes}$ hydraulic hand dynamometer was used to evaluate the coarse grip strength of the hands. Finger grip strength was assessed with a Baseline $e^{ø}$ pinch meter. Measurements were made bilaterally from three different positions (lateral, fingertip, and palmar). Each bilateral measurement was performed three times and averaged. (10)

\section{Disease Activity Score (DAS28)}

In this study, disease activity was evaluated with the DAS28 scoring system. The basic criteria of this system are the sensitivity of the joints, number of swollen joints, sedimentation, and general health assessment using the Visual Analog Scale (VAS). (11)

\section{Health Assessment Questionnaire (HAQ)}

HAQ was used to evaluate the daily life activities of the patients. HAQ is a health assessment questionnaire developed to evaluate rheumatic diseases, especially RA. It consists of 20 questions under eight activity domains inquiring about daily tasks, namely dressing/general care, sitting/standing up, eating, walking, hygiene, lying down, and grip. Each response is graded from 0 to 3. The HAQ score reflects functional status and its score has been shown to correlate with disease activity indicators. (12)

\section{Statistical Analysis}

Statistical analyses were carried out using the Statistical Package for the Social Sciences (IBM SPSS Statistics 14). Frequency tables and descriptive statistics were used in the interpretation of findings. Non-parametric methods were used for measurement values that were not suitable for normal distribution. The MannWhitney $U$ test (Z-table value) was employed to compare the measurement values of two independent groups in accordance with the parametric methods. The Spearman correlation coefficient was used to examine the relationships between two non-normally distributed quantitative variables. $\mathrm{P}$ value $<0.05$ was accepted as statistically significant.

\section{RESULTS}

The demographic characteristics of the 80 patients with RA and 50 healthy volunteers constituting the control group are given in Table 1.

\begin{tabular}{|lcccc|}
\hline \multicolumn{1}{|c|}{ Table 1. Sociodemographic data table } & & \\
& \multicolumn{2}{c}{ RA Group } & Control Group \\
\cline { 2 - 5 } & n & \% & N & \% \\
\hline Age, years & 6 & 7.5 & 5 & 10 \\
$20-35$ & 22 & 27.5 & 22 & 44 \\
$35-50$ & 52 & 65 & 23 & 46 \\
$50-65$ & & & & \\
Gender & 66 & 82.5 & 39 & 78 \\
Female & 14 & 17.5 & 11 & 22 \\
Male & & & & \\
\hline RA, rheumatoid arthritis & & & & \\
\hline
\end{tabular}


While $65 \%$ of 80 patients with RA were seropositive, $35 \%$ were seronegative. There was no patient with systemic involvement. The mean disease duration in the RA group was 7.09 \pm 5.64 months. The dominant hand was right in 78 patients $(96 \%)$ and left in two (4\%) while all controls were right-handed. The mean DAS28 value of the patients with RA was $3.17 \pm 0.82$, and according to this result, their disease activity was detected to be at a mild (<3.2) level. As an inclusion criterion, patients without hand deformities were included in the sample.

The mean HAQ score was $0.37 \pm 1.45$ for the RA group and $0.61 \pm 0.42$ for the control group. No statistically significant difference was found between the two groups in terms of daily life activities ( $p>0.05)$. The mean DHI was $4.67 \pm 7.58$ and $0.02 \pm 0.14$ in the RA and control groups, respectively, indicating a statistically significant deterioration in the fine skills of the hands in the former compared to the latter $(\mathrm{p}<0.001)$.

\section{DAS28, HAQ and DHI Scores and Their Relationship with Disease Duration}

The relationship of the DAS28, HAQ and DHI scores with disease duration among the 80 patients in the RA group is presented in Table 2. A positive significant correlation was found between disease activity and DHI in the RA group $(\mathrm{r}=0.483, \mathrm{p}=0.001)$. There was also a significant positive correlation between disease activity and quality of life scores $(r=0.504, p=0.001)$. However, no significant correlation was observed between disease duration and disease activity level ( $\mathrm{p}>0.05)$. P value $<0.05$ was accepted as statistically significant.

\begin{tabular}{|c|c|c|c|}
\hline & DAS28 & HAQ & DHI \\
\hline DHI & $\begin{array}{l}\mathrm{P}=0.001 \\
\mathrm{r}=0.483\end{array}$ & $\begin{array}{l}\mathrm{p}=0.001 \\
\mathrm{r}=0.865\end{array}$ & \\
\hline DAS28 & & $\begin{array}{l}\mathrm{p}=0.001 \\
\mathrm{r}=0.504\end{array}$ & $\begin{array}{l}\mathrm{p}=0.001 \\
\mathrm{r}=0.483\end{array}$ \\
\hline HAQ & $\begin{array}{l}\mathrm{p}=0.001 \\
\mathrm{r}=0.504\end{array}$ & & $\begin{array}{l}\mathrm{p}=0.001 \\
\mathrm{r}=0.865\end{array}$ \\
\hline Disease duration & $\begin{array}{l}\mathrm{p}=0.087 \\
\mathrm{r}=0.193\end{array}$ & $\begin{array}{l}\mathrm{p}=0.031 \\
\mathrm{r}=0.241\end{array}$ & $\begin{array}{l}\mathrm{p}=0.036 \\
\mathrm{r}=0.234\end{array}$ \\
\hline
\end{tabular}

\section{Relationship between the SWMT Results, DAS28, DHI and HAQ Scores and Disease Duration in the RA Group}

In the sensory examination of the RA group using SWMT, $83 \%(n=67)$ of the patients were evaluated as normal with the green monofilament (log 1.65-2.83), $15 \%(n=12)$ as diminished light touch sensation with the blue monofilament ( $\log 3.22-3.61$ ), and only $1.3 \%$ $(n=1)$ as diminished protective sensation with the purple filament. For all the healthy controls, the SWMT sensory evaluation result was normal with the green monofilament. However, no statistical difference was found in the sensory evaluation results of the RA and control groups $(p>0.05)$. P value $<0.05$ was accepted as statistically significant.

In the RA group, we also divided the SWMT sensory examination results into group 1 (green monofilament/ normal) and group 2 (blue monofilament/diminished light touch sensation) for further analyses. We found no statistical difference between groups 1 and 2 in terms of the DAS28, HAQ and DHI scores and disease duration $(\mathrm{p}>0.05)$.

\section{Relationship between Grip and Pinch Values and DAS28, DHI, HAQ Scores of the RA Group}

A negative correlation was found between the grip and pinch values and DAS28, DHI and HAQ scores, and this was a statistically significant level $(\mathrm{p}<0.001)$. Increased disease activity and decreased hand dexterity significantly affected the grip function of the hands in the patients with RA. P value $<0.05$ was accepted as statistically significant.

\begin{tabular}{|c|c|c|c|c|c|}
\hline & & DAS28 & DHI & HAQ & $\begin{array}{c}\text { Disease } \\
\text { duration }\end{array}$ \\
\hline SWMT & $\begin{array}{l}\text { Group } 1 \\
\text { (green) }\end{array}$ & $3.15 \pm 077$ & $4.71 \pm 7.9$ & $0.4 \pm 1.5$ & $6.46 \pm 4.7$ \\
\hline \multirow[t]{2}{*}{ SWMT } & $\begin{array}{l}\text { Group } 2 \\
\text { (blue) }\end{array}$ & $3.26 \pm 1.08$ & $4.58 \pm 5.48$ & $4.58 \pm 5.48$ & $10.5 \pm 8.8$ \\
\hline & $P$ value & 0.6 & 0.54 & 0.54 & 0.19 \\
\hline
\end{tabular}

\begin{tabular}{|c|c|c|c|c|c|c|c|c|}
\hline & $\begin{array}{c}\text { Right hand } \\
\text { grip }\end{array}$ & $\begin{array}{l}\text { Left hand } \\
\text { grip }\end{array}$ & $\begin{array}{l}\text { Right lateral } \\
\text { pinch }\end{array}$ & $\begin{array}{l}\text { Left lateral } \\
\text { pinch }\end{array}$ & $\begin{array}{c}\text { Right tip } \\
\text { pinch }\end{array}$ & Left tip pinch & $\begin{array}{l}\text { Right palmar } \\
\text { pinch }\end{array}$ & $\begin{array}{l}\text { Left palmar } \\
\text { pinch }\end{array}$ \\
\hline DAS 28 & $\begin{array}{l}\mathrm{p}=0.001 \\
\mathrm{r}=-0.497\end{array}$ & $\begin{array}{l}\mathrm{p}=0.001 \\
\mathrm{r}=-0.526\end{array}$ & $\begin{array}{l}\mathrm{p}=0.001 \\
\mathrm{r}=-0.459\end{array}$ & $\begin{array}{l}\mathrm{p}=0.001 \\
\mathrm{r}=-0.439\end{array}$ & $\begin{array}{l}\mathrm{p}=0.001 \\
\mathrm{r}=-0.371\end{array}$ & $\begin{array}{l}\mathrm{p}=0.001 \\
\mathrm{r}=-0.348\end{array}$ & $\begin{array}{l}\mathrm{p}=0.001 \\
\mathrm{r}=-0.491\end{array}$ & $\begin{array}{l}\mathrm{p}=0.001 \\
\mathrm{r}=-0.450\end{array}$ \\
\hline DHI & $\begin{array}{l}\mathrm{p}=0.001 \\
\mathrm{r}=-0.545\end{array}$ & $\begin{array}{l}\mathrm{p}=0.001 \\
\mathrm{r}=-0.583\end{array}$ & $\begin{array}{l}\mathrm{p}=0.001 \\
\mathrm{r}=-0.601\end{array}$ & $\begin{array}{l}\mathrm{p}=0.001 \\
\mathrm{r}=-0.572\end{array}$ & $\begin{array}{l}\mathrm{p}=0.001 \\
\mathrm{r}=-0.487\end{array}$ & $\begin{array}{l}\mathrm{p}=0.001 \\
\mathrm{r}=-0.402\end{array}$ & $\begin{array}{l}\mathrm{p}=0.001 \\
\mathrm{r}=-0.575\end{array}$ & $\begin{array}{l}\mathrm{p}=0.001 \\
\mathrm{r}=-0.531\end{array}$ \\
\hline HAQ & $\begin{array}{l}\mathrm{p}=0.001 \\
\mathrm{r}=-0.556\end{array}$ & $\begin{array}{l}\mathrm{p}=0.001 \\
\mathrm{r}=-0.581\end{array}$ & $\begin{array}{l}\mathrm{p}=0.001 \\
\mathrm{r}=-0.566\end{array}$ & $\begin{array}{l}\mathrm{p}=0.001 \\
\mathrm{r}=-0.513\end{array}$ & $\begin{array}{l}\mathrm{p}=0.001 \\
\mathrm{r}=-0.482\end{array}$ & $\begin{array}{l}\mathrm{p}=0.001 \\
\mathrm{r}=-0.452\end{array}$ & $\begin{array}{l}\mathrm{p}=0.001 \\
\mathrm{r}=-0.598\end{array}$ & $\begin{array}{l}\mathrm{p}=0.001 \\
\mathrm{r}=-0.575\end{array}$ \\
\hline
\end{tabular}

RA, rheumatoid arthritis; DAS, Disease Activity Score; HAQ, Health Assessment Questionnaire; DHI, Duru Oz Hand Index 


\section{Relationship between Wrist Dorsiflexion Limitation and HAQ, DHI and DAS28 Scores}

The relationship between wrist dorsiflexion limitation and HAQ, DHI and DAS28 scores was evaluated with the Spearman correlation test. There were no volunteers with wrist dorsiflexion limitation in the control group. In the RA group, we observed that as wrist dorsiflexion limitation increased, the HAQ, DHI and DAS28 scores increased, but this increase was not statistically significant ( $p>0.05)$. P value $<0.05$ was accepted as statistically significant.

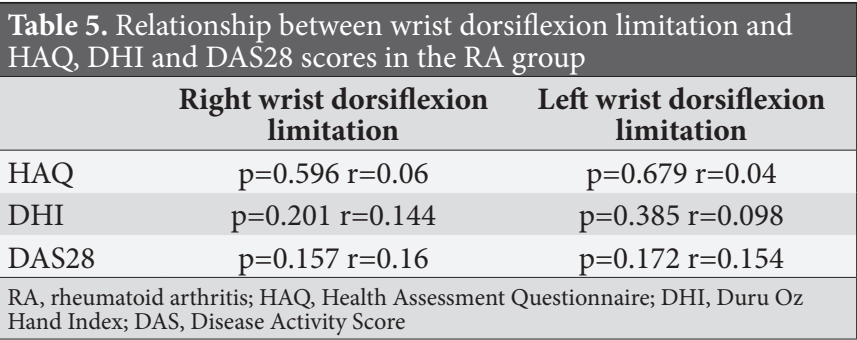

\section{DISCUSSION}

In this study, we evaluated hand sensorimotor functions in patients with RA and investigated their relationship with daily life activities and disease specific parameters. In the literature, the sensory evaluation of the hands in patients with RA has not been addressed as much as motor evaluation. However, it has been reported that proinflammatory cytokines and proteolytic enzymes, which are shown to be produced by tenosynovium in patients with RA, may cause sensory disturbances by affecting mechanoreceptors found in the tendons and myotendinous junctions (13). Therefore, the second stage of our study was designed to include a sensory evaluation.

In the literature, many tests and scales have been used in the evaluation of sensorimotor functions. DHI, which was developed by Duru Oz et al. $(8,14,15)$ in 1996 , has entered clinical practice as a self-report scale for the assessment and monitoring of functional disability in rheumatoid hands. In a study conducted with 102 patients with RA, Dedeoğlu et al. (16) find a strong relationship between daily life activity (HAQ) and hand function (DHI) . In our study, there was no statistical difference between the RA and control groups in terms of the HAQ scores. However, a significant correlation was detected between daily life activities (HAQ) and hand skill functions (DHI). This finding is an indication that hand functions occupy an important place in daily life activities. In our study, the mean DHI of the RA group was higher than that of the control group. Although there was no difference in the HAQ scores between the two groups, the statistical difference observed in the DHI averages proves once again that tests evaluating manual skills better reflect hand functions in rheumatoid hands than a general health assessment.

In a study in which 151 female and 45 male patients with RA were included, it was shown that increased disease activity significantly affected the daily life in RA patients (17). In another study 752 patients with RA were followed up for three years and the patients with low DAS28 scores were found to have higher quality of life(18). In our study, consistent with the literature, a significant correlation was observed between the daily life activities and disease activity scores of the patients. Similar to our findings, Birtane et al. (19) who evaluated 48 patients with RA, reported strong correlations between disease activity, daily life activities and hand functions. In another study, Özeri et al. (20) determined that functional impairment of the hand, disability, and joint damage had a strong relationship with disease duration, wrist range of motion, and grip strength in patients with RA.As a result, the authors argued that wrist range of motion and grip strength could be used to predict disability and joint damage in clinical practice.

Silva et al., comparing patients with RA and controls, found that the grip strength decreased in the RA group with high DAS28 activity (21). Similarly, in our study, a significant correlation was found between both fine skill and grip functions of the hands and disease activity scores. The increase in disease activity negatively was observed to negatively affect the quality of life and hand functions the patients.

In a study in which 153 patients with RA were retrospectively evaluated, there was a significant correlation between the HAQ and DAS28 scores, and a strong correlation between increased disease duration and disease activity (22). In our study, daily life activities and hand functions were significantly affected in the RA group among the patients with a longer disease duration, while a weaker correlation was observed between disease duration and activity. We consider this to be due to the low disease activity scores of the RA cases included in our study.

There was a negative correlation between the grip and pinch values and disease activity, daily life activities, and fine skill level in our patients with RA, and this was found to be at a statistically significant level. Consistent with the literature (23), We consider that diminished grip strength significantly affects daily life activities and hand dexterity functions and is an important cause of disability. Supporting our findings, Dedeoğlu et al. (16) also found a significant negative relationship between hand grip strength and finger grip strength, as well as hand functions and general disability level. 
It was determined that the increase in wrist dorsiflexion limitation affect the daily life activities and hand functions of the patients and resulted in an increase their disease activity scores. In parallel with our study, in a study conducted by Taştekin et al. (24), limitations in the range of motion and impaired hand functions were determined to cause difficulties in daily life activities.

SWMT is a quantitative method for sensory evaluation. In the literature, it has mostly been employed in diseases such as tendon damage, diabetic neuropathy, and carpal tunnel syndrome (25-27). In a study by Silva et al. (28), patients with systemic sclerosis accompanied by distal phalanx deformities were compared with another patient group without deformity, and the former was found to have diminished light touch. In our knowledge there is no study with SMWT in RA patients. In our study, there was no statistical difference between the RA and control groups in terms of sensory evaluation with SMWT.

Potential limitations of our study are that the number of patients was relatively small and have low disease activity and no hand deformity. Another limitation of our study is that subgroups with chronic diseases such as DM, cervical radicular pain etc. were not differentiated.

\section{CONCLUSION}

As a result of the quantitative evaluations used in our study, the RA group was determined to have impaired fine skills and grip strength. Consistent with the literature, these findings had a negative effect on the daily life activities and function of these patients. SMWT sensory examination results were not statistically different between RA patients and control group. Because of our patients have low disease activity, further studies are needed in patients with higher disease activity for evaluation sensorial functions.

\section{ETHICAL DECLARATIONS}

Ethics Committee Approval: The study was carried out with the permission of Ankara Yıldırım Beyazıt University Faculty of Medicine Clinical Researchs Ethics Committee (Date: 17/12/2014, Decision No: 243).

Informed Consent: All patients signed the free and informed consent form.

Referee Evaluation Process: Externally peer-reviewed.

Conflict of Interest Statement: The authors have no conflicts of interest to declare.

Financial Disclosure: The authors declared that this study has received no financial support.

Author Contributions: All of the authors declare that they have all participated in the design, execution, and analysis of the paper, and that they have approved the final version.

\section{REFERENCES}

1. Towheed TE, Anastassiades TP. Rheumatoid hand practical approach to assessment and management. Can Fam Physician 1994; 40: 1303-9.

2. Dellhag B, Bjelle A. A five-year followup of hand function and activities of daily living in rheumatoid arthritis patients. Arthritis care and research, 1999, 12: 33-41.

3. Bodur H, Yilmaz O, Keskin D. Hand disability and related variables in patients with rheumatoid arthritis. Rheumatology international, 2006, 26.6: 541-544.

4. Calder KM, Martin A, Lydiate J, MacDermid J, Galea V, MacIntyre N. Sensory nerve action potentials and sensory perception in women with arthritis of the hand. J Neuroengineer Rehabil 2012; 9: 27-37.

5. Muramatsu K, Tanaka H, Taguchi T. Peripheral neuropathies of the forearm and hand in rheumatoid arthritis: diagnosis and options for treatment. Rheumatol Int 2008; 28: 951-7. 9.

6. Dellhag B, Hosseini N, Bremel T, Ingvarsson PE. Disturbed grip function in women with rheumatoid arthritis. J Rheumatol 2001; 28: 2624-33. 9.

7. Dellhag B, Burckhardt CS. Predictors of hand function in patients with rheumatoid arthritis. Arthrit Rheumat 1995; 8: 16-20.

8. Duruöz M T, Poiraudeau S, Fermanian J, et al. Development and validation of a rheumatoid hand functional disability scale that assesses functional handicap. Journal Rheumatol 1996; 23: 1167 72 .

9. Mathiowetz V, Weber K, Kashman N. Adult norms for the nine hole peg test of finger dexterity. OTJR: Occupat Participat Health 1985; 5: 24-38.

10. Mathiowetz V, Weber K, Kashman N, Volland G, et al. Grip and pinch strength evaluations. J Hand Surg 1984; 9A: 223-5.

11.M Van Riel, Kanıtlanmış romatoid artritli hastaların değerlendirilmesi ve sonuçları. (Karatay S Çev.Ed) Hochberg romatoloji cilt 1. Rota Tip yayıevi İzmir 2011; 357-64.

12. Küçükdeveci AA, Sahin H, Ataman S, Griffiths B, Tennant A. Issues in cross-cultural validity: example from the adaptation, reliability, and validity testing of a Turkish version of the Stanford Health Assessment Questionnaire. Arthritis Rheum 2004; 51: 14.

13. Erol A M,Ceceli E, Ramadan S, Borman P. Sensory examination of rheumatoid hand and the relationship with magnetic resonance imaging findings. Ege Tip Derg / Ege J Med 2014; 53: 200-20.

14.Duruöz MT. Romatizmal hastalıkların değerlendirilmesinde kullanılan fonksiyonel el göstergeleri. Türk Fiz Tıp Rehab Derg 1998; 3: 44.

15. Gürçay E, Alanoğlu E, Tuncay R,Uşan H, Çakçı A. Romatoid elde Duruöz el skalasının ve kavrama beceri testinin değerlendirilmesi. Turkiye Klinikleri J Physic Med Rehabilit 2004, 4: 1-6.

16. Dedeoğlu M, Gafuroğlu U, Yılmaz Ö, Bodur H. The relationship between hand grip and pinch strengths and disease activity, articular damage, pain, and disability in patients with rheumatoid arthritis.Turk J Rheumatol 2013; 28: 69-77.

17.Prajs K, Fliciński J, Brzosko I, Przepiera-Bedzak H, Ostanek L, Brzosko M. Quality of life and activity of disease in patients with rheumatoid arthritis. Ann Acad Med Stetin 2006; 52: 39-43.

18. Gullick NJ, Ibrahım F, Scott IC, et al. Real world long term impact of intensive treatment on disease activity, disability and healthrelated quality of life in rheumatoid arthritis. BMC Rheumatol 2019; 3: 6 .

19. Birtane M, Kabayel D, Uzunca $K$, et al. The relation of hand functions with radiological damage and disease activity in rheumatoid arthritis. Rheumatol Int 2008, 28: 407-12.

20.Özeri Z, Duyur Çakıt B, Taşkın S, Genç H, Saraçoğlu M, Erdem HR. The Relationships Among Functional Impairment, Disability and Articular Damage in Rheumatoid Hand. FTR Bil Der J PMR Sci 2008; 2: 53-8. 
21. Silva G, Lourenço M, Assis M. Hand strength in patients with RA corralates strongly with function but not with activity of disease. Adv Rheumatol 2018; 58: 20

22. Çetin E, Çağlar N, Örnek GT, et al. Demographic and clinical properties and the current medical treatments. Istanbul Med J 2010; 11: 154-8.

23. Wolfe F, Cathey MA. The assessment and prediction of functional disability in rheumatoid arthritis.J Rheumatol 1991; 18: 1298-306.

24. Taştekin N, Uzunca K, Birtane M, Kabayel D, Öztürk G. Romatoid artritli hastalarda, el eklemlerindeki hareket açıklığı ve el kavrama kuvvetlerinin hastalık aktivasyonu, el fonksiyonları ve özürlülük ile ilișkisi. Romatizma 2006; 21: 13-7.

25. Craig AB, Strauss MB, Daniller A, Miller S. Foot sensation testing in the patient with diabetes: introduction of the quick and easy assessment tool. Wounds 2014; 26: 221-31.

26. Raji P, Ansari NN, Naghdi S , Forogh B, Hasson S. Relationship between Semmes-Weinstein monofilaments perception test and sensory nerve conduction studies in carpal tunnel syndrome. J NeuroRehabilitation 2014; 35: 543-52.

27. McCallister WV, Ambrose HC, Katolik LI, Trumble TE. Comparison of pullout button versus suture anchor for zone I flexor tendon repair. J Hand Surg Am 2006; 31: 246-51.

28. Silva PG, Jones A, Araujo PM, Natour JÜ. Assessment of light touch sensation in the hands of systemic sclerosis patients. Clinics (Sao Paulo) 2014; 69: 585. 